\title{
The Diagnostic and Prognostic Significance of MicroRNA-21 in Non-muscle Invasive Bladder Tumors
}

\author{
(1) Önder Çınar MD, ® Necmettin Aydın Mungan MD \\ Zonguldak Bülent Ecevit University Faculty of Medicine, Department of Urology, Zonguldak, Turkey
}

\begin{abstract}
Bladder cancer $(B C)$ is one of the commonly diagnosed urological cancers that causes human death, ranked as the seventh most common cancer worldwide. To date, no reliable diagnostic tool has been defined to recognize non-muscle invasive bladder tumors other than cystoscopy. For this reason, scientists have focused on finding new non-invasive biomarkers that can be used to diagnose BC with higher specificity and sensitivity. The purpose of this study was to evaluate the diagnostic role and prognostic significance of microRNA-21 (miR-21) in non-muscle invasive bladder tumors. In this review, the overall diagnostic performance of miR-21 was discussed on non-invasive BC based on a literature search of PubMed and Cochrane Library. Although findings are insufficient, promising results have been reported regarding circulating miR-21 as a biomarker for BC prospective studies with larger numbers of participants are needed.
\end{abstract}

Keywords: Non-muscle invasive bladder tumor, microRNA-21, diagnostic marker

\section{Introduction}

Bladder cancer $(B C)$ is one of the urological cancers that causes the most deaths worldwide. It is the seventh most commonly diagnosed cancer (1). In 2016, more than 76,000 newly diagnosed cases of BC were reported in the United States and more than 16,000 of those resulted in death (2). BC is 3-4 times more common in men than in women (3). There are geographic variations in the incidence of $B C$ and smoking has an important role in its etiology (4).

$B C$ is classified into two main groups, non-muscle invasive $B C$ (NMIBC) and muscle-invasive BC (MIBC), based on its pathologic and clinical features (5). Approximately $70 \%$ of cases are NMIBC at initial diagnosis, and the 5-year survival rate after endoscopic resection of these tumors is around $80 \%$ $(6,7,8)$. In $50-70 \%$ of NMIBC cases, recurrence is observed in the first two years, while $10-20 \%$ of cases progress to MIBC, in which the chance of 5 -year survival decreases to $56 \%(9,10)$. Although it does not require life-long follow-up, patients diagnosed with BC face invasive procedures like cystoscopy, as well as associated complications such as infections and trauma, due to the frequency of recurrence in the first two years. Progression to MIBC is detected in $20-30 \%$ of patients with high-risk superficial $B C$ treated with transurethral resection (TUR) followed by intravesical Bacillus Calmette-Guérin (BCG) therapy (11). Early detection of progression is important because the mortality rate is as high as $44 \%$ in MIBC, which can progress rapidly and metastasize despite the availability of effective treatment strategies $(8,9,12,13)$. Although various diagnostic tools and biological markers have been developed to predict the recurrence and progression of NMIBC, most have been shown to have inadequate efficacy and accuracy due to the heterogeneous nature of BC $(14,15,16)$. BC is diagnosed by cystoscopy and urine cytology as well as tumor markers like nuclear matrix protein-22 (NMP-22) and bladder tumor antigen (BTA). The most sensitive of these diagnostic methods is the combination of cystoscopy and urine cytology $(17,18)$. Although cystoscopy is regarded as the gold standard method for the diagnosis of BC, its main disadvantages are that it is invasive, causes patient discomfort, and must be performed by a urologist (19). While urine cytology is a non-invasive method, it is generally more successful in the diagnosis of high-grade and high-stage BCs compared to low-grade tumors (20). NMP22 and BTA are currently used as urinary biomarkers and are simple, rapid, and non-invasive tests for BC screening. NMP22 and BTA have specificity of $47-100 \%$ and $29-83 \%$ and sensitivity of $55-98 \%$ and $56-86 \%$, respectively, and therefore they cannot be recommended as ideal diagnostic methods $(21,22,23)$. Non-invasive biomarkers with higher sensitivity and specificity are needed to enable earlier detection of BC. For this reason, new biomarkers should be identified that can be used alone or in combination with parameters affecting $\mathrm{BC}$ prognosis in order to identify patients with poor prognosis in advance. MicroRNAs (miRNA) are single-stranded, non-coding RNA gene products, usually 22 nucleotides in length, that are involved in the regulation of gene expression (24). Recent studies suggest that abnormal miRNA structures are associated with the development, progression, and prognosis of various human 
cancers $(25,26)$. Non-invasive biomarkers for the diagnosis of $B C$ can be developed from urinary or circulating miRNAs $(27,28,29,30,31,32,33,34)$.

In this study, we address the diagnostic value and prognostic significance of miRNA-21 in NMIBC.

\section{Discussion}

MicroRNA molecules are single-stranded, non-coding gene products 22 nucleotides in length whose roles in human disease are being investigated (35). These molecules posttranscriptionally regulate gene expression by binding to the $3^{\prime}$-UTR region of target mRNAs, resulting in the degradation or translational inhibition of the target mRNA (36). After these molecules that regulate gene expression and various biological processes were first identified in 1993, they were later reported to also affect proliferation, apoptosis, metabolism, and immune mechanisms. The up- or down-regulation of miRNA has been established as a biomarker in numerous cancer types and, accordingly, is thought to have potential utility in the diagnosis or prognosis of various cancers of colorectal (37), breast (38), lung (39), and ovarian $(40)$ origin $(25,26,41,42)$. It has been shown that bladder tumors, like other known solid tumors, also contain hypoxic regions and that excessive release of hypoxia-inducible markers is associated with poor prognosis (43). In 2015, Blick et al. (44) demonstrated that miRNA-210, miRNA-193b, miRNA-145, miRNA-125-3p, miRNA-708, and miRNA-517 were associated with hypoxia in BC cells. The same study demonstrated the functional significance of hypoxiainduced miRNAs and showed that miRNA-145 controlled BC cell apoptosis. miRNA-21 was shown to have a p53-mediated anti-apoptotic effect by specifically targeting programmed cell death mRNAs $(45,46)$. A study conducted by Liu et al. $(47)$ in 2011 showed that the overexpression of miRNA-21 in a prostate cancer cell line increased the release of hypoxia-induced factor 1 alpha (HIF-1a) and vascular endothelial growth factor.

miRNA studies on the diagnosis and prognosis of $B C$ showed that these molecules can be obtained from urine (27-34). Although the patient's age and sex or the presence of hematuria may adversely affect the biomarker quality of miRNA, detection of miRNA in urine should be considered an important finding in terms of BC. In recent years, studies have been published on the prognostic significance of different miRNA molecules in patients with BC. In 2016, Zhang et al. (48) reported that miRNA-155 analysis in cell-free urine samples of NMIBC patients had diagnostic value with $85.8 \%$ sensitivity. In another study investigating the role of miRNA-203 in predicting treatment response in patients planned to start cisplatin-based chemotherapy for BC, it was reported that low miRNA-203 level predicted progression and poor prognosis while overexpression of miRNA-203 may increase the sensitivity to cisplatin by directly stimulating apoptosis (49). It was also reported that miRNA-214 down-regulates oncogenic P53 and DNA damageregulated gene 1 and that this is a determining factor in $B C$ prognosis (50). In 2010, Kiemeney et al. (51) expanded their earlier study on Dutch and Icelandic populations to include some European countries, increasing the number of patients to 4,739 and the number of controls to 45,549 , and examined the relationship between DNA variants and $B C$ using the 20 best known markers. In this study, they demonstrated that the T allele of rs798766 on 4p16.3 was associated with low-grade and noninvasive $\mathrm{BC}(51)$.

miRNA-21, which is considered an oncogene, is frequently upregulated in BC patients and supports tumor cell proliferation and metastasis by interfering with tumor suppressor checkpoints $(52,53)$. Although it is believed that miRNA-21 may have utility as a diagnostic and prognostic biomarker because of its increased release in certain cancers, there are conflicting reports concerning its diagnostic power and prognostic value. One of these was a meta-analysis by Wang et al. (54) in which a total of 528 studies were reviewed and the results of 17 studies that met the study criteria were used to evaluate the relationship between miRNA-21 levels and survival in patients with cancer. Eleven of these studies focused on the diagnostic value of miRNA-21 and 9 studies evaluated prognosis, and plasma miRNA-21 was determined to have sensitivity and specificity of $75.7 \%$ and $79.3 \%$, respectively, when used as a diagnostic biomarker. Because coagulation could affect miRNA21 expression, serum miRNA-21 measurements were also evaluated but no difference was found in terms of sensitivity and specificity (54). A limitation of this meta-analysis was that it did not include studies investigating the relationship between miRNA-21 and BC. In a study examining the relationship between bile duct cancers and miRNA-21, Kishimoto et al. (55) reported its negative predictive value (NPV) as $76.6 \%$. Kotb et al. (56) reported this rate as $90 \%$ for prostate cancer. In a study investigating response to preoperative chemoradiotherapy in locally advanced rectal cancers, the NPV for miRNA-21 was found to be $42.8 \%$ (57). While it is not surprising that the NPV of miRNA-21 varied for different cancer types in these studies, there is currently no ongoing or completed study showing the NPV of miRNA-21 in BC. In a 2015 study by Zhang et al. (58), TUR was performed on 53 patients with $B C$ who had not received neoadjuvant therapy and RNA was extracted from the specimens. They formed a control group by obtaining healthy bladder tissue from patients who underwent TURprostatectomy (TUR-P) due to benign prostate hyperplasia. Patient characteristics such as age, tumor grade, tumor number, stage, and size, recurrence rates, and lymph node involvement were recorded. They determined that miRNA-21 expression was upregulated in $\mathrm{BC}$ tissues compared to normal bladder tissues. Upregulation of miRNA-21 was associated with tumor stage, grade, and lymph node metastasis, but not with patient sex, age, tumor size, number of tumors, or recurrence. However, the authors cited the small patient number as a limitation of the study and acknowledged that more extensive studies are needed (59).

Mitash et al. (60) conducted another study with a limited number of cases and short follow-up period, in which they reported that increased miRNA-21 expression was associated with recurrence in NMIBC and that miRNA-21 level was negatively correlated with time to recurrence. It has long been known that high-grade T1 NMIBC is prone to recurrence. The epithelial-mesenchymal transition (EMT) promotes tumor cell proliferation, invasion, and migration, thereby increasing tumor aggressiveness. Histopathologic findings of vimentin 
upregulation and e-cadherin down-regulation, which are indirect indicators of EMT (61), plus miRNA-21 overexpression also indicates the tumor will undergo an aggressive transformation $(62,63)$. In a study investigating the critical role of miRNA-21 in cell proliferation, apoptosis, and chemosensitivity in addition to its oncogenic role in $\mathrm{BC}$, it was reported that this molecule will facilitate the differential diagnosis between NMIBC and MIBC. With that study, the authors reported for the first time that increased miRNA-21 level conferred chemoresistance against doxorubicin, an agent used in the treatment of $B C$, through different mechanisms by stimulating down-regulation in the T24 cell line and that it carried the potential for developing treatment strategies for $B C$ in the future (64).

\section{Conclusion}

The results of the few studies demonstrating the importance of miRNA-21 in monitoring BC and predicting prognosis are promising despite some limitations. Extensive prospective studies with larger patient numbers are needed to determine the utility of miRNA-21 as a biomarker.

\section{Ethics}

Peer-review: Externally peer-reviewed.

Authorship Contributions

Consept: N.A.M., Ö.Ç., Design: N.A.M., Ö.Ç., Data Collection and Processing: Ö.ç., Analysis and Interpretation: N.A.M., Ö.Ç., Literature Search: Ö.Ç., Writing: Ö.Ç.

Conflict of Interest: No conflict of interest was declared by the authors.

Financial Disclosure: The authors declared that this study received no financial support.

\section{References}

1. Ferlay J, Soerjomataram I, Ervik M, et al. GLOBOCAN 2012: Estimated cancer incidence, mortality and prevalence worldwide in 2012. V1.0. International Agency for Research on Cancer 2012.

2. Siegel RL, Miller KD, Jemal A. Cancer statistics, 2016. CA Cancer J Clin 2016;66:7-30.

3. Malats N, Real FX. Epidemiology of bladder cancer. Hematol Oncol Clin North Am 2015;29:177-189.

4. Chavan S, Bray F, Lortet-Tieulent J, et al. International variations in bladder cancer incidence and mortality. Eur Urol 2014;66:59-73.

5. Sanguedolce F, Bufo P, Carrieri G, Cormio L. Predictive markers in bladder cancer: do we have molecular markers ready for clinical use? Crit Rev Clin Lab Sci 2014;51:291-304.

6. Siegel R, Naishadham D, Jemal A. Cancer statistics, 2013. CA Cancer J Clin 2013;63:11-30.

7. Matsuda T, Hori M. Five-year relative survival rate of bladder cancer in the USA, Europe and Japan. Jpn J Clin Oncol 2014;44:776.

8. Goodison S, Rosser C], Urquidi V. Bladder cancer detection and monitoring: assessment of urine- and blood-based marker tests. Mol Diagn Ther 2013;17:71-84.

9. Kaufman DS, Shipley WU, Feldman AS. Bladder cancer. Lancet 2009;374:239-249.

10. Arcangeli G, Arcangeli S, Strigari L. A systematic review and metaanalysis of clinical trials of bladder-sparing trimodality treatment for muscle-invasive bladder cancer (MIBC). Crit Rev Oncol Hematol 2015;94:105-115.
11. Messing EM. Urothelial tumors of the bladder. In: Wein AJ, Kavoussi LR, Novick AC, et al, eds. Campbell-Walsh urology. 9th ed. Philadelphia: Saunders; 2007. p. 2426-2427.

12. Smith ZL, Guzzo TJ. Urinary markers for bladder cancer. F1000Prime Rep 2013;5:21.

13. Shelley MD, Mason MD, Kynaston H. Intravesical therapy for superficial bladder cancer: a systematic review of randomised trials and meta-analyses. Cancer Treat Rev 2010;36:195-205.

14. Wu TT, Chen JH, Lee YH, Huang JK. The role of bcl-2, p53, and ki67 index in predicting tumor recurrence for low grade superficial transitional cell bladder carcinoma. J Urol 2000;163:758-760.

15. Quan C, Park MS, Jo SW, et al. Effects of transforming growth factor-beta1 and its receptor on the development, recurrence and progression of human bladder cancer. Korean J Urol 2006;47:426-435.

16. Ha YS, Yun SJ, Kim YJ, et al. Utility of Smo as a prognostic marker for human bladder tumors. Korean J Urol 2007;48:997-1003.

17. Tetu B. Diagnosis of urothelial carcinoma from urine. Mod Pathol 2009;22(Suppl 2):53-59.

18. Nakamura K, Kasraeian A, Iczkowski KA, et al. Utility of serial urinary cytology in the initial evaluation of the patient with microscopic hematuria. BMC Urol 2009;9:12.

19. Grossman HB, Soloway M, Messing E, et al. Surveillance for recurrent bladder cancer using a point-of-care proteomic assay. JAMA 2006;295:299-305.

20. Parker J, Spiess PE. Current and emerging bladder cancer urinary biomarkers. Scientific World Journal 2011;11:1103-1112.

21. Todenhöfer T, Hennenlotter J, Guttenberg P, et al. Prognostic relevance of positive urine markers in patients with negative cystoscopy during surveillance of bladder cancer. BMC Cancer 2015;15:155.

22. Miremami J, Kyprianou N. The promise of novel molecular markers in bladder cancer. Int J Mol Sci 2014;15:23897-23908.

23. Chao D, Freedland SJ, Pantuck AJ, et al. Bladder cancer 2000: molecular markers for the diagnosis of transitional cell carcinoma. Rev Urol 2001;3:85-93.

24. Ebert MS, Sharp PA. Roles for microRNAs in conferring robustness to biological processes. Cell 2012;149:515-524.

25. Croce CM, Calin GA. miRNAs, cancer, and stem cell division. Cell 2005; 122:6-7.

26. Lieberman J, Slack F, Pandolfi PP, et al. Noncoding RNAs and cancer. Cell 2013;153:9-10.

27. Zhang DZ, Lau KM, Chan ES, et al. Cell-free urinary microRNA-99a and microRNA-125b are diagnostic markers for the non-invasive screening of bladder cancer. Plos One 2014;9:e100793.

28. Jiang $X$, Du L, Wang $L$, et al. Serum microRNA expression signatures identified from genomewide microRNA profiling serve as novel noninvasive biomarkers for diagnosis and recurrence of bladder cancer. Int J Cancer 2015; 136:854-862.

29. Tölle A, Jung $M$, Rabenhorst $S$, et al. Identification of microRNAs in blood and urine as tumour markers for the detection of urinary bladder cancer. Oncol Rep 2013;30:1949-1956.

30. Mengual L, Lozano JJ, Ingelmo-Torres $M$, et al. Using microRNA profiling in urine samples to develop a non-invasive test for bladder cancer. Int J Cancer 2013;133:2631-2641.

31. Adam L, Wszolek MF, Liu CG, et al. Plasma microRNA profiles for bladder cancer detection. Urol Oncol 2013;31:1701-1708.

32. Miah S, Dudziec E, Drayton RM, et al. An evaluation of urinary microRNA reveals a high sensitivity for bladder cancer. Br J Cancer 2012;107:123-128.

33. Snowdon J, Boag S, Feilotter H, Izard J, Siemens DR. A pilot study of urinary microRNA as a biomarker for urothelial cancer. Can Urol Assoc J 2013;7:28-32.

34. Zhou X, Zhang $X$, Yang $Y$, et al. Urinary cell-free microRNA-106b as a novel biomarker for detection of bladder cancer. Med Oncol 2014;31:197. 
35. Dietrich D, Meller S, Uhl B, et al. Nucleic acid-based tissue biomarkers of urologic malignancies. Crit Rev Clin Lab Sci 2014;51:173-199.

36. Shukla GC, Singh J, Barik S. MicroRNAs: Processing, Maturation, Target Recognition and Regulatory Functions. Mol Cell Pharmacol 2011;3:83-92.

37. Ma W, Yu Q, Jiang J, et al. miR-517a is an independent prognostic marker and contributes to cell migration and invasion in human colorectal cancer. Oncol Lett 2016;11:2583-2589.

38. Hu JY, Yi W, Wei X, et al. miR-601 is a prognostic marker and suppresses cell growth and invasion by targeting PTP4A1 in breast cancer. Biomed Pharmacother 2016;79:247-253.

39. Jiang LP, Zhu ZT, He CY. Expression of miRNA-26b in the diagnosis and prognosis of patients with non-small-cell lung cancer. Future Oncol 2016;12:1105-1115.

40. Wang F, Chang JT, Kao Cl, Huang RS. High expression of miR-532-5p, a tumor suppressor, leads to better prognosis in ovarian cancer both in vivo and in vitro. Mol Cancer Ther 2016;15:1123-1131.

41. Tilki D, Burger $M$, Dalbagni $G$, et al. Urine markers for detection and surveillance of non-muscle-invasive bladder cancer. Eur Urol 2011;60:484-492.

42. Cortez MA, Bueso-Ramos C, Ferdin J, et al. MicroRNAs in body fluids--the mix of hormones and biomarkers. Nat Rev Clin Oncol 2011;8:467-477.

43. Ord JJ, Agrawal S, Thamboo TP, et al. An investigation into the prognostic significance of necrosis and hypoxia in high grade and invasive bladder cancer. J Urol 2007;178:677-682.

44. Blick C, Ramachandran A, McCormick R, et al. Identification of a hypoxia-regulated miRNA signature in bladder cancer and a role for miR-145 in hypoxia-dependent apoptosis. Br J Cancer 2015; 113:634-644.

45. Papagiannakopoulos T, Shapiro A, Kosik KS. MicroRNA-21 targets a network of key tumor-suppressive pathways in glioblastoma cells. Cancer Res 2008;68:8164-8172.

46. Lu Z, Liu M, Stribinskis V, et al. MicroRNA-21 promotes cell transformation by targeting the programmed cell death 4 gene. Oncogene 2008;27:4373-4379.

47. Liu LZ, Li C, Chen Q, et al. MiR-21 induced angiogenesis through AKT and ERK activation and HIF-1 $\alpha$ expression. PLOS ONE. 2011;6:19139.

48. Zhang X, Zhang Y, Liu X, et al. Direct quantitative detection for cellfree miR-155 in urine: a potential role in diagnosis and prognosis for nonmuscle invasive bladder cancer. Oncotarget 2016;7:3255-3266.

49. Zhang X, Zhang Y, Liu X, et al. MicroRNA-203 Is a Prognostic Indicator in Bladder Cancer and Enhances Chemosensitivity to Cisplatin via Apoptosis by Targeting Bcl-w and Survivin. Plos One 2015; 10:e0143441.

50. Wang J, Zhang X, Wang L, et al. MicroRNA-214 suppresses oncogenesis and exerts impact on prognosis by targeting PDRG1 in bladder cancer. PLoS One 2015;10:e0118086.
51. Kiemeney LA, Sulem P, Besenbacher $S$, et al. A sequence variant at $4 p 16.3$ confers susceptibility to urinary bladder cancer. Nat Genet 2010;42:415-419.

52. Musavi SM, Mansoori B, Mohammadi A, et al. SiRNA-mediated silencing of Snail-1 induces apoptosis and alters micro RNA expression in human urinarybladder cancer cell line. Artif Cells Nanomed Biotechnol 2017;45:969-974.

53. Lei M, Xie W, Sun E, et al. microRNA-21 Regulates Cell Proliferation and Migration and Cross Talk with PTEN and p53 in Bladder Cancer. DNA Cell Biol 2015;34:626-632.

54. Wang $Y$, Gao X, Wei F, et al. Diagnostic and prognostic value of circulating miR-21 for cancer: a systematic review and meta-analysis. Gene 2014;533:389-397.

55. Kishimoto T, Eguchi $H$, Nagano $H$, et al. Plasma miR-21 is a novel diagnostic biomarker for biliary tract cancer. Cancer Sci 2013; 104:1626-1631.

56. Kotb S, Mosharafa A, Essawi M, et al. Circulating miRNAs 21 and 221 as biomarkers for early diagnosis of prostate cancer. Tumour Biol 2014;35:12613-12617.

57. Caramés C, Cristóbal I, Moreno V, et al. MicroRNA-21 predicts response to preoperative chemoradiotherapy in locally advanced rectal cancer. Int J Colorectal Dis 2015;30:899-906.

58. Zhang HH, Qi F, Cao YH, et al. Expression and clinical significance of microRNA-21, maspin and vascular endothelial growth factor-C in bladder cancer. Oncol Lett 2015;10:2610-2616.

59. Zhang HH, Qi F, Cao YH, et al. Expression and clinical significance of microRNA-21, maspin and vascular endothelial growth factor-C in bladder cancer. Oncol Lett 2015;10:2610-2616.

60. Mitash N, Agnihotri S, Tiwari S, Agrawal V, Mandhani A. MicroRNA-21 could be a molecular marker to predict the recurrence of nonmuscle invasive bladder cancer. Indian J Urol 2017;33:283-290.

61. Morata Tarifa C, Jiménez G, García MA, et al. Low adherent cancer cell subpopulations are enriched in tumorigenic and metastatic epithelial to mesenchymal transition induced cancer stem like cells. Sci Rep 2016;6:18772.

62. Wszolek MF, Rieger-Christ KM, Kenney PA, et al. A MicroRNA expression profile defining the invasive bladder tumor phenotype. Urol Oncol 2011;29:794-801.

63. Neely LA, Rieger-Christ KM, Neto BS, et al. A microRNA expression ratio defining the invasive phenotype in bladder tumors. Urol Oncol 2010;28:39-48.

64. Tao J, Lu Q, Wu D, et al. microRNA-21 modulates cell proliferation and sensitivity to doxorubicin in bladder cancer cells. Oncol Rep 2011;25:1721-1729. 